\title{
Lack of Association between Statin Use and Angiographic and Clinical Outcomes after Pipeline Embolization for Intracranial Aneurysms
}

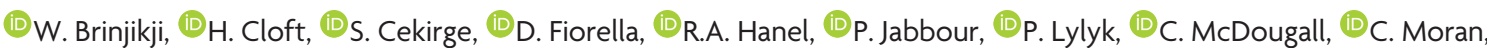 \\ (1) A. Siddiqui, (1)I. Szikora, and (1DD.F. Kallmes
}

\begin{abstract}
BACKGROUND AND PURPOSE: Use of statin medications has been demonstrated to improve clinical and angiographic outcomes in patients receiving endovascular stent placement for coronary, peripheral, carotid, and intracranial stenoses. We studied the impact of statin use on long-term angiographic and clinical outcomes after flow-diverter treatment of intracranial aneurysms.
\end{abstract}

MATERIALS AND METHODS: We performed a post hoc analysis from pooled patient-level datasets from 3 Pipeline Embolization Device studies: the International Retrospective Study of the Pipeline Embolization Device, the Pipeline for Uncoilable or Failed Aneurysms Study, and the Aneurysm Study of Pipeline in an Observational Registry. We analyzed data comparing 2 subgroups: 1) patients on statin medication, and 2) patients not on statin medication at the time of the procedure and follow-up. Angiographic and clinical outcomes were compared by using the $\chi^{2}$ test, Fisher exact test, or Wilcoxon rank sum test.

RESULTS: We studied 1092 patients with 1221 aneurysms. At baseline, 226 patients were on statin medications and 866 patients were not on statin medications. The mean length of clinical and angiographic follow-up was $22.1 \pm 15.1$ months and $28.3 \pm 23.7$ months, respectively. There were no differences observed in angiographic outcomes at any time point between groups. Rates of complete occlusion were $82.8 \%$ $(24 / 29)$ versus $86.4 \%(70 / 81)$ at 1-year $(P=.759)$ and $93.3 \%(14 / 15)$ versus $95.7 \%(45 / 47)$ at 5 -year $(P=1.000)$ follow-up for statin-versusnonstatin-use groups, respectively. There were no differences in any complication rates between groups, including major morbidity and neurologic mortality $(7.5 \%$ versus $7.1 \%, P=.77)$.

CONCLUSIONS: Our study found no association between statin use and angiographic or clinical outcomes among patients treated with the Pipeline Embolization Device.

ABBREVIATION: PED = Pipeline Embolization Device

S

tatin medications are among the most commonly prescribed in the adult population and have been found beneficial in improving clinical and angiographic outcomes of a number of endovascular neurovascular, cardiovascular, and peripheral vascular stent-placement procedures. ${ }^{1-3}$ Both experimental and clin-

Received August 9, 2016; accepted after revision November 22.

From the Department of Radiology (W.B., H.C., D.F.K.), Mayo Clinic, Rochester, Minnesota; Department of Radiology (S.C.), Koru Hospital and Bayindir Hospitals, Ankara, Turkey; Department of Neurosurgery (D.F.), Cerebrovascular Center, Stony Brook University Medical Center, Stony Brook, New York; Stroke and Cerebrovascular Surgery (R.A.H.), Lyerly Neurosurgery/Baptist Neurological Institute, Jacksonville, Florida; Department of Neurosurgery (P.J.), Thomas Jefferson University, Philadelphia, Pennsylvania; Department of Neurosurgery (P.L.), Equipo de Neurocirugía Endovascular y Radiología Intervencionista de Buenos Aires-Clinica La Sagrada Familia, Buenos Aires, Argentina; Department of Endovascular Neurosurgery (C.McDougall), Barrow Neurological Institute, Phoenix, Arizona; Division of Interventional Neuroradiology (C.Moran), Mallinckrodt Institute of Radiology, Washington University School of Medicine, St. Louis, Missouri; Department of Neurosurgery (A.S.), University at Buffalo Neurosurgery, Buffalo, New York; and Department of Neurointerventional Services (I.S.), National Institute of Clinical Neurosciences, Budapest, Hungary.

This work was supported by Medtronic. ical studies have demonstrated that statin use is associated with improved endothelialization of implanted stents, which can reduce the rates of delayed in-stent thrombosis and in-stent stenosis. ${ }^{4-6}$ In the treatment of aneurysms with flow diverters such as the Pipeline Embolization Device (PED; Covidien, Irvine, California), stent endothelialization has been shown to play a key role in aneurysm occlusion rates and in reducing the risk of delayed in-stent thrombosis.?

Given the widespread acceptance and use of flow-diverter therapy in the treatment of intracranial aneurysms, it is important to know what effect, if any, statins have on clinical and angiographic outcomes. To gain a better understanding of the impact of statins on short- and long-term outcomes after flow

Please address correspondence to Waleed Brinjikji, MD, Mayo Clinic, Department of Radiology, 200 1st St SW, Rochester, MN 55905; e-mail: brinjikji.waleed@mayo. edu; @wbrinjikji

三 Indicates article with supplemental on-line table.

http://dx.doi.org/10.3174/ajnr.A5078

AJNR Am J Neuroradiol 38:753-58 Apr 2017 www.ajnr.org 
diversion for intracranial aneurysms, we studied angiographic and clinical outcomes of patients included in 3 large clinical studies of the PED: the Pipeline for Uncoilable or Failed Aneurysms Study (PUFS), ${ }^{8}$ the International Retrospective Study of the Pipeline Embolization Device (IntrePED), ${ }^{9}$ and the Aneurysm Study of Pipeline in an Observational Registry (ASPIRe), ${ }^{10}$ dividing patients into 2 groups: 1) those who were on a statin medication at the time and following treatment with the PED, and 2) those who were not on statin medications. ${ }^{8,9}$ The goal of this study was to determine whether statin use is associated with angiographic occlusion and major neurologic morbidity and mortality after PED treatment. We hypothesized that patients on statin medications would have a lower rate of in-stent stenosis and morbidity and mortality rates and improved angiographic occlusion rates.

\section{MATERIALS AND METHODS Patient Population}

Patients were selected from the PUFS, ${ }^{8}$ IntrePED, ${ }^{9}$ and ASPIRe ${ }^{10}$ studies. PUFS was a prospective single-arm clinical trial of 108 patients with 108 aneurysms, which included only patients with wide-neck (or no discernable neck) ( $\geq 4 \mathrm{~mm}$ ) and large (10-24.9 $\mathrm{mm}$ ) or giant ( $\geq 25 \mathrm{~mm}$ ) aneurysms of the internal carotid artery from the petrous to the superior hypophyseal segments with a follow-up of 5 years. IntrePED was a retrospective postmarket registry of 793 patients with 906 aneurysms with no size or location eligibility criteria with a follow-up time of up to 3 years. ASPIRe was a prospective postmarket registry of 191 patients with 207 aneurysms in which size and location inclusion criteria followed the country-specific PED instruction for use with a follow-up time of up to 2 years. The patients included in this study have already been included in previous studies, which did not focus on the impact of statins on clinical and angiographic outcomes.

We pooled data from these 3 studies, including patients with unruptured and ruptured aneurysms, in which information on the use of statin medications was available. Patients were retrospectively divided into 2 groups: 1) patients on statin medication at the time and following the procedure, and 2) patients not on statin medication. The following baseline characteristics were included in the analysis: age, sex, number of aneurysms, aneurysm size, aneurysm type (saccular, fusiform, dissecting, and other), aneurysm location, rupture status, and use of multiple PEDs.

\section{Outcomes}

The primary outcome analyzed from this pooled analysis included aneurysm occlusion at last follow-up, and secondary outcomes analyzed were the following: major ipsilateral ischemic stroke, ipsilateral intracranial hemorrhage, all-cause mortality, and in-stent stenosis at last follow-up. "Major" adverse events were defined as ongoing clinical deficits at 7 days following the event. All major ipsilateral ischemic stroke and major ipsilateral intracranial hemorrhage events are included in the neurologic morbidity rate. The safety events described above, namely ipsilateral ischemic stroke, ipsilateral intracranial hemorrhage, and neurologic mortality, were adjudicated by the Adverse Events Review Committee of each study. An independent core lab adjudicated all angiographic outcomes of aneurysm occlusion and stenosis. All 3 studies, ASPIRe, IntrePED, and PUFS, collected clinical outcomes ( $n=1221$ aneurysms), while ASPIRe and PUFS collected angiographic outcomes in addition $(n=209)$. Angiographic outcomes are reported at 180 days and 1,3 , and 5 years.

\section{Statistical Analysis}

Statistical analyses were performed by using SAS, Version 9.2 (SAS Institute, Cary, North Carolina). Summary statistics are presented for all data available by using means and SDs for continuous variables and frequency tabulations for categoric variables. Comparisons between groups for continuous variables were evaluated by using the Wilcoxon rank sum test, Fisher exact test, or Pearson $\chi^{2}$ test for binary categoric variables. Most statistical analyses were performed across patient groups-that is, on a per-patient basis. Because some patients had $>1$ aneurysm, however, each patient's first aneurysm treated was used to classify patients into the 4 anatomic/size subgroups and the largest aneurysm was used to classify patients into the 3 aneurysm size categories. The first aneurysm treated was defined a priori.

A post hoc power analysis was conducted to determine the size of the difference between groups that could be detected with $80 \%$ power, given the sample sizes in the subgroups and the event rates in the nonstatin group. The results show that the analysis cohort has $80 \%$ power to detect a difference of approximately $20 \%$ for the angiographic outcome of complete occlusion at the last follow-up visit. For the clinical outcomes, the analysis cohort has $80 \%$ power to detect differences of approximately $2 \%-4 \%$ for event rates of $3 \%-7 \%$ in the nonstatin group.

A multivariable logistic regression analysis was performed to determine whether statin use was independently associated with the above outcomes. Adjusted variables in this model were baseline variables that were significantly different between groups (ie, age, multiple PED use, aneurysm type, and aneurysm size) and studies. For the multivariable analysis, the nonstatin group was the reference group. All interactions among the parameter of interest, statin use, and the other covariates were tested for each of the outcomes. In each interaction model, for the continuous parameters of age and aneurysm size, odds ratios were calculated at the quartiles of $25 \%, 50 \%$, and $75 \%$. Each interaction model controlled for all other covariates.

\section{RESULTS}

\section{Baseline Patient and Aneurysm Characteristics}

A total of 1092 patients with 1221 treated aneurysms were included. Clinical follow-up was available for 1092 patients. Angiographic follow-up of at least 6 months was available for 209 patients. Baseline demographics and aneurysm characteristics according to the statin status are presented in Table 1 .

The mean age of all patients was $57.4 \pm 13.7$ years. The mean length of follow-up was $22.1 \pm 15.1$ months for the clinical outcomes with a median follow-up time of 19.9 months. Mean follow-up time was $28.3 \pm 23.7$ months for the angiographic outcomes. There were 226 patients with 265 aneurysms (24.3\% of 
Table 1: Baseline demographics and aneurysm characteristics

\begin{tabular}{|c|c|c|c|}
\hline Subject Characteristics & Statin Use & No Statin Use & $P$ Value \\
\hline Age (yr) & & & $<.001$ \\
\hline Mean \pm SD (No.) & $64.6 \pm 9.6(225)$ & $55.5 \pm 14.0(863)$ & \\
\hline Median (range) & $65.0(39.0-85.0)$ & $56.0(3.0-89.0)$ & \\
\hline Sex & & & .251 \\
\hline Male & $15.9 \%(36 / 226)$ & $19.4 \%(168 / 866)$ & \\
\hline Female & $84.1 \%(190 / 226)$ & $80.6 \%(698 / 866)$ & \\
\hline \multicolumn{4}{|l|}{ Hypertension } \\
\hline Yes & $75.5 \%(123 / 163)$ & $41.1 \%(289 / 703)$ & $<.001$ \\
\hline Controlled & $91.3 \%(95 / 104)$ & $83.5 \%(207 / 248)$ & .065 \\
\hline Not controlled & $22.1 \%(36 / 163)$ & $53.8 \%(378 / 703)$ & \\
\hline No. of aneurysms & 265 & 956 & \\
\hline Aneurysm size (mm) & & & .716 \\
\hline Mean \pm SD (No.) & $11.6 \pm 7.0(261)$ & $12.1 \pm 8.0(950)$ & \\
\hline Median (range) & $10.2(1.5-32.6)$ & $10.2(0.9-55.0)$ & \\
\hline Aneurysm neck (mm) & & & .868 \\
\hline Mean \pm SD (No.) & $6.6 \pm 4.9(231)$ & $6.6 \pm 4.8(891)$ & \\
\hline Median (range) & $5.6(0.6-53.0)$ & $5.3,(0.0-50.0)$ & \\
\hline Aneurysm size & & & .385 \\
\hline Small & $36.4 \%(95 / 261)$ & $39.9 \%(379 / 950)$ & \\
\hline Large & $54.8 \%(143 / 261)$ & $50.0 \%(475 / 950)$ & \\
\hline Giant & $8.8 \%(23 / 261)$ & $10.1 \%(96 / 950)$ & \\
\hline Aneurysm type & & & .001 \\
\hline Saccular & $70.9 \%(188 / 265)$ & $76.3 \%(729 / 956)$ & \\
\hline Fusiform & $20.8 \%(55 / 265)$ & $14.9 \%(142 / 956)$ & \\
\hline Dissecting & $1.9 \%(5 / 265)$ & $5.8 \%(55 / 956)$ & \\
\hline Other & $6.4 \%(17 / 265)$ & $3.1 \%(30 / 956)$ & \\
\hline Aneurysm location & & & .208 \\
\hline Internal carotid artery & $81.9 \%(217 / 265)$ & $79.5 \%(760 / 956)$ & \\
\hline Middle cerebral artery & $2.6 \%(7 / 265)$ & $4.1 \%(39 / 956)$ & \\
\hline Posterior cerebral artery & $0.0 \%(0 / 265)$ & $1.7 \%(16 / 956)$ & \\
\hline Basilar artery & $4.5 \%(12 / 265)$ & $4.0 \%(38 / 956)$ & \\
\hline Other & $10.9 \%(29 / 265)$ & $10.8 \%(103 / 956)$ & \\
\hline Presented with ruptured aneurysm & $4.5 \%(12 / 265)$ & $6.7 \%(64 / 956)$ & .197 \\
\hline Multiple PEDs used & $43.9 \%(116 / 264)$ & $35.2 \%(336 / 954)$ & .009 \\
\hline
\end{tabular}

Table 2: Angiographic outcomes (PUFS and ASPIRe only)

\begin{tabular}{lllc}
\hline \multicolumn{1}{c}{ Follow-Up } & \multicolumn{1}{c}{ Statin Use } & No Statin Use & $\boldsymbol{P}$ Value \\
\hline Complete occlusion at 180 days (-20/+42 days) & $84.8 \%(28 / 33)$ & $72.2 \%(83 / 115)$ & .174 \\
Complete occlusion at 1 year ( \pm 42 days) & $82.8 \%(24 / 29)$ & $86.4 \%(70 / 81)$ & .759 \\
Complete occlusion at 3 years & $94.7 \%(18 / 19)$ & $93.0 \%(53 / 57)$ & 1.000 \\
Complete occlusion at 5 years & $93.3 \%(14 / 15)$ & $95.7 \%(45 / 47)$ & 1.000 \\
Complete occlusion at last follow-up visit & $76.4 \%(42 / 55)$ & $83.8 \%(129 / 154)$ & .227 \\
\hline
\end{tabular}

${ }^{a}$ Analysis was performed with the Pearson $\chi^{2}$ test.

Table 3: Clinical outcomes ${ }^{\mathrm{a}}$

\begin{tabular}{lccc}
\hline \multicolumn{1}{c}{ Major Complication } & Statin Use & No Statin Use & $\boldsymbol{P}$ Value \\
\hline Major ipsilateral ischemic stroke & $4.9 \%(11 / 226)$ & $3.4 \%(29 / 865)$ & .319 \\
Major ipsilateral intracranial hemorrhage & $0.9 \%(2 / 226)$ & $2.3 \%(20 / 865)$ & .284 \\
Major morbidity & $5.8 \%(13 / 226)$ & $5.7 \%(49 / 865)$ & 1.000 \\
Neurologic mortality & $3.5 \%(8 / 226)$ & $3.2 \%(28 / 865)$ & .835 \\
Major morbidity and neurologic mortality & $7.5 \%(17 / 226)$ & $7.1 \%(61 / 865)$ & .773 \\
All-cause mortality & $4.4 \%(10 / 226)$ & $3.9 \%(34 / 865)$ & .706 \\
\hline
\end{tabular}

${ }^{a}$ Analysis was performed with the Pearson $\chi^{2}$ test.

aneurysms) on statin medications (40 patients from ASPIRe, 162 patients from IntrePED, and 24 patients from PUFS) and 866 patients with 956 aneurysms (75.7\% of aneurysms) not on statin medications (151 patients from ASPIRe, 631 patients from IntrePED, and 84 patients from PUFS). In general, baseline characteristics were similar between groups except that patients receiving statin medications were older $(64.6 \pm 9.6$ years versus $55.5 \pm$ 14.0 years, $P<.001)$ and more likely to have hypertension $(75.5 \%$ versus $41.1 \%, P<.001)$. Patients on statins were less likely to have saccular aneurysms, but the difference was not statistically significant $(188 / 265$, $70.9 \%$, versus $729 / 956,76.3 \% ; P=$ .078). Statin patients were more likely to have multiple PEDs (116/264, 43.9\%, versus $336 / 954,35.2 \% ; P=.009$ ).

\section{Angiographic and Clinical \\ Outcomes}

Angiographic outcomes are presented in Table 2. Clinical outcomes are provided in Table 3. There were no differences in angiographic occlusion rates at last follow-up between the statin $(76.4 \%, 42 /$ $55)$ and nonstatin use groups $(83.8 \%$, $129 / 154)(P=.23)$. There were no differences in angiographic complete occlusion rates in the statin use-versus-no statin use subject groups at 6 months (84.8\% versus $72.2 \%, P=.17)$, 1 year (82.8\% versus $86.4 \%, P=.76)$, 3 years (94.7\% versus $93.0 \%, P=1.00)$, and 5 years $(93.3 \%$ versus $95.7 \%, P=1.00)$. Rates of in-stent stenosis of $50 \%-75 \%$ at last follow-up were $0 \%(0 / 43)$ in the statin group and $1.4 \%(2 / 139)$ in the nonstatin group $(P=1.00)$. Rates of in-stent stenosis of $>75 \%$ were $4.7 \%(2 / 43)$ in the statin group and $0.7 \%(1 / 139)$ in the nonstatin group $(P=.14)$.

There were no differences in major complication rates between groups. The ipsilateral ischemic stroke rate was $4.9 \%$ $(11 / 226)$ in the statin group and $3.4 \%$ $(29 / 865)$ in the nonstatin group $(P=$ .32). Combined major neurologic morbidity and mortality rates were $7.5 \%$ $(17 / 226)$ in the statin group and $7.1 \%$ $(61 / 865)$ in the nonstatin group $(P=$ $.77)$.

\section{Multivariable Analysis}

The multivariable logistic regression analysis is presented in Table 4 . The odds of all complications and angiographic outcomes were similar between the statin and nonstatin groups, after adjusting for study, age, multiple PED use, aneurysm type, and aneurysm size. There were no statistically significant interactions between statin use and other covariates in the multivariable models (On-line Table).

\section{DISCUSSION}

Our study of $>1000$ patients with 1221 treated aneurysms demonstrates that statin use was not associated with improved angiographic and clinical outcomes among patients undergoing PED treatment of intracranial aneurysms. These findings are impor- 
Table 4: Multivariable logistic regression analysis

\begin{tabular}{|c|c|c|c|c|}
\hline Outcome: Major Complications & $\begin{array}{l}\text { OR (Statin } \\
\text { vs No Statin) }\end{array}$ & $\begin{array}{l}\text { 95\% Lower } \\
\text { Bound }\end{array}$ & $\begin{array}{l}95 \% \text { Upper } \\
\text { Bound }\end{array}$ & $P$ Value \\
\hline All-cause mortality & 0.72 & 0.34 & 1.53 & .397 \\
\hline Major ipsilateral intracranial hemorrhage & 0.31 & 0.09 & 1.14 & .078 \\
\hline Major ipsilateral ischemic stroke & 1.43 & 0.66 & 3.09 & .362 \\
\hline Major morbidity & 0.83 & 0.42 & 1.64 & .593 \\
\hline Major morbidity and neurologic mortality & 0.80 & 0.44 & 1.47 & .478 \\
\hline Neurologic mortality & 0.65 & 0.28 & 1.47 & .298 \\
\hline Stenosis $>50 \%$ at last follow-up & 2.83 & 0.53 & 15.09 & .224 \\
\hline $\begin{array}{l}\text { Without complete aneurysm occlusion at } \\
\text { last follow-up }\end{array}$ & 1.20 & 0.54 & 2.66 & .657 \\
\hline
\end{tabular}

tinuation of dual antiplatelet therapy, delayed endothelialization of drug-eluting stents used to treat atherosclerotic lesions and flow-diverter stents used to treat intracranial aneurysms has been shown to portend higher rates of delayed in-stent thrombosis, which can lead to significant morbidity and mortality. ${ }^{21,22}$ Endothelialization of the flow-diverter stent has been shown to be essential to achieving complete occlusion rates as well. ${ }^{7,21}$ Given the benefits of statins in

tant because they suggest that unlike stent procedures performed for treatment of atherosclerotic lesions in the coronary, peripheral, and cerebrovascular circulation, statin therapy for patients receiving flow-diverter stent treatment of intracranial aneurysms is not associated with improved clinical or angiographic outcomes. A key limitation to our study is that it was powered to show a $>20 \%$ difference in angiographic outcomes and an approximately $2 \%-4 \%$ difference in clinical outcomes between groups.

Prior studies in the cardiovascular and cerebrovascular literature have demonstrated that statin therapy improves clinical and angiographic outcomes in patients undergoing stent placement procedures for atherosclerotic diseases. In a study of 122 patients receiving intracranial stent placement for vertebrobasilar atherosclerosis, Alexander et $\mathrm{al}^{11}$ found that statin treatment before an intervention was associated with lower odds of death, stroke, and disability at 1 year. In a study of 344 patients receiving carotid stent placement for carotid artery stenosis, Reiff et $\mathrm{al}^{6}$ found that patients who were on statin therapy before an intervention had lower rates of perioperative stroke, death, myocardial infarction, and intracranial hemorrhage. One systematic review of carotid stent placement demonstrated that statin therapy was associated with a reduction of stroke and mortality rates at 1 month. ${ }^{12}$

In the cardiovascular literature, several studies have demonstrated that statin therapy improved neointimal coverage of drugeluting stents and also reduced rates of neointimal hyperplasia. ${ }^{4,13-16}$ In addition, statin use has also been shown to improve short-term mortality rates in patients receiving stent placement for acute coronary syndrome due to reductions in thrombotic complication rates. In a study of $>1500$ patients, Tentzeris et $\mathrm{al}^{5}$ found that patients on high-dose statin therapy had lower odds of mortality at 3 months. In a subgroup analysis of the Basel Stent Kosten Effektivitas Trial (BASKET), Jeger et $\mathrm{al}^{17}$ found that statins reduced short- and long-term rates of in-stent thrombosis. Studies in the peripheral vascular literature have also demonstrated the benefits of statins in clinical and angiographic outcomes. ${ }^{18}$

This study is the first, to our knowledge, to specifically analyze the impact of statins on angiographic and clinical outcomes after PED treatment of intracranial aneurysms. Understanding the effect of statins on outcomes related to the PED is important because previous studies have shown that statins are beneficial in patients receiving endovascular stent treatment of atherosclerotic lesions in various vascular beds due to their role not only in plaque stabilization but also in promoting vessel wall healing and endothelialization of stent struts. ${ }^{1,6,11,19,20}$ In addition to early discon- the atherosclerotic literature, we hypothesized that similar results would be seen in flow diverters.

A number of mechanisms have been proposed for the improved endothelialization of implanted stents in patients on statin therapy and reduced rates of thrombotic complications. Statins have a number of non-lipid-lowering effects, also known as "pleiotropic effects," which affect systemic inflammatory responses, endothelial function through upregulation of endothelial nitric oxide synthase, modulation of inflammation, platelet adhesion, and mobilization of endothelial progenitor cells. ${ }^{1,19,20}$ In a porcine model of drug-eluting stent implantation, 1 group demonstrated that atorvastatin accelerated re-endothelialization of the stent through mobilization of endothelial progenitor cells and improvement of endothelial function. ${ }^{23}$ In a study of 9 patients receiving percutaneous coronary intervention for coronary artery disease, Aoki et $\mathrm{al}^{24}$ found that patients who were given olmesartan and statin therapy had high levels of circulating endothelial progenitor cells. Other clinical studies have demonstrated similar results. ${ }^{25}$

In addition to improved endothelialization, statins could have other pleiotropic effects on aneurysms that would result in improved outcomes following flow-diverter therapy. In 1 recently published study, Aoki et $\mathrm{al}^{26}$ found that pivastatin had a suppressive effect on cerebral aneurysm progression by inhibiting the NF- $\kappa$ B pathway in aneurysm walls and regression of degenerative changes within the wall itself. In a separate study, Aoki et $\mathrm{al}^{27}$ also found that simvastatin suppressed aneurysm development and progression in rats by inhibiting aneurysm wall inflammation. Inhibition of aneurysm growth following endovascular treatment is particularly important because some studies have suggested that aneurysm growth plays a role in recurrence.

A number of factors could explain the lack of clinical and angiographic benefits of statins in patients receiving PEDs for intracranial aneurysms. First, statins are thought to reduce periprocedural complications in patients undergoing stent placement for atherosclerotic lesions due to their role in plaque stabilization. ${ }^{28}$ In addition, many of the benefits of statins in reducing early in-stent thrombosis are thought to be secondary to their anti-inflammatory effects. While unstable or vulnerable plaques in patients with acute coronary syndrome or acute ischemic stroke are known to produce both local and systemic inflammatory responses, this outcome is not necessarily true in the case of unruptured aneurysms, which are most of the lesions treated with the PED. ${ }^{29}$ Regarding the role of statins in stent endothelialization, it may be that statin therapy is more important in accelerating endothelialization when the stent is closely apposed to an 
inflamed atherosclerotic plaque that could potentiate thrombogenesis than to a normal or dysplastic intracranial vessel that does not demonstrate atheromatous disease.

\section{Limitations}

Our study has several limitations. It is a retrospective study, including datasets from several studies with various inclusion and exclusion criteria. There is a risk of introducing bias and confounding factors when mixing prospective and retrospective studies with various levels of follow-up. Given the rarity of the complications studied, our study is underpowered to detect important clinical differences between groups. For example, there was a clinically significant but not statistically significant difference in the odds of intracerebral hemorrhage in the statin group compared with the nonstatin group. Because our study analyses were post hoc, we did not perform a power calculation before data collection. However, our study is the largest one examining the association between statin use and outcomes of intracranial aneurysm treatment with flow diverters to date, to our knowledge. Another limitation concerns our multivariable analyses. Logistic regression models were used without censoring. However, while there were differing lengths of follow-up, most clinical events occurred early in follow-up ( $<10 \%$ were later than 6 months' postindex treatment), while the median follow-up time was approximately 20 months.

The patients in our study were divided into those who were or were not on statins during the study period. However, we did not determine outcomes based on statin type and dose. It is possible that more potent statins or higher statin doses could produce a more robust therapeutic effect. In addition, we have no information regarding serum cholesterol levels; thus, the association between serum cholesterol and outcomes could not be ascertained. As mentioned previously, there were important baseline differences between patients in both groups. Namely, patients in the statin group were more likely to have nonsaccular aneurysms, suggesting that more of their aneurysms could be atherosclerotic in nature. Last, we have no data or information as to whether statin users were managed differently than nonstatin users.

\section{CONCLUSIONS}

Our study, which was powered to show a $>20 \%$ difference in angiographic outcomes and a $2 \%-4 \%$ difference in clinical outcomes between groups, found no association between statin use and aneurysm occlusion rates, in-stent stenosis, or clinical outcomes after PED treatment of intracranial aneurysms. Future studies examining statin effects should use more rigorously matched controls and fewer variables.

Disclosures: David Fiorella—RELATED: Consulting Fee or Honorarium: ev3/Covidien*; Support for Travel to Meetings for the Study or Other Purposes: ev3/Covidien, Comments: lectures and proctor cases; UNRELATED: Consultancy: Penumbra, Sequent Medical, Codman \& Vascular Simulations*; Grants/Grants Pending: Siemens, Penumbra, Sequent Medical, MicroVention*; Royalties: Codman Johnson \& Johnson*; Stock/Stock Options: Vascular Simulations. Ricardo A. Hanel—RELATED: Consulting Fee or Honorarium: Medtronic, Comments: consultant and proctor fees; UNRELATED: Consultancy: Stryker, Codman, MicroVention; Grants/Grants Pending: MicroVention*; Stock/Stock Options: Blockade. Pascal Jabbour-UNRELATED: Consultancy: Medtronic; Grants/Grants Pending: Medtronic.* Pedro Lylyk—UNRELATED: Travel/Accommodations/Meeting Expenses Unrelated to Activities Listed: Covidien, Cardiatis, Sequent Medical, MicroVention, Phenox. Cameron McDougall-
UNRELATED: Consultancy: Medtronic, MicroVention, Comments: consultant, proctor for the Pipeline Embolization Device, Data and Safety Monitoring Board for the INTREPED study, Principal Investigator for the MicroVention FRED trial. Christopher Moran-RELATED: Grant: Medtronic*; UNRELATED: Consultancy: Medtronic; Grants/Grants Pending: Medtronic*; Payment for Lectures Including Service on Speakers Bureaus: Medtronic; Payment for Development of Educational Presentations: Medtronic; Travel/Accommodations/Meeting Expenses Unrelated to Activities Listed: Medtronic. Adnan Siddiqui-RELATED: Consulting Fee or Honorarium: Covidien (acquired by Medtronic); Other: Covidien (now Medtronic), Solitaire With the Intention For Thrombectomy as PRIMary Endovascular Treatment (SWIFT PRIME) and SWIFT DIRECT trials, Comments: National Steering Committees; UNRELATED: Board Membership: Intersocietal Accreditation Committee; Consultancy: Codman \& Shurtleff, Medtronic, GuidePoint Global, Penumbra, Stryker, MicroVention, W.L. Gore \& Associates, Three Rivers Medical, Corindus, Amnis Therapeutics, CereVasc, Pulsar Vascular, The Stroke Project, Cerebrotech Medical Systems, Rapid Medical, Lazarus (acquired by Medtronic), Medina Medical (acquired by Medtronic), Reverse Medical (acquired by Medtronic), Covidien (acquired by Medtronic), Neuroavi, Silk Road Medical, Rebound Medical; Stock/Stock Options: StimSox, Valor Medical, Neuro-Technology Investors, Cardinal Health, Medina Medical Systems, Buffalo Technology Partners, International Medical Distribution Partners; Other: Penumbra, 3D Separator Trial; Covidien (now Medtronic), SWIFT PRIME and SWIFT DIRECT trials; MicroVention, FRED trial; MicroVention, CONFIDENCE study, LARGE trial, POSITIVE trial, Penumbra; COMPASS trial; Penumbra, INVEST trial, Comments: National Steering Committees. Istvan Szikora—RELATED: Consulting Fee or Honorarium: Covidien; UNRELATED: Consultancy: Medtronic, Stryker, Codman, Sequent Medical. David F. Kallmes_RELATED: Grant: Medtronic, Comments: Principal Investigator of clinical trials*; Consulting Fee or Honorarium: Medtronic, Comments: Clinical Event Committee*; Support for Travel to Meetings for the Study or Other Purposes: Medtronic, Comments: travel to FDA panel meeting to present trial results*; Fees for Participation in Review Activities such as Data Monitoring Boards, Statistical Analysis, Endpoint Committees, and the Like: Medtronic, Comments: Clinical Events Committee*; UNRELATED: Board Membership: GE Healthcare, Comments: CostEffectiveness Board*; Consultancy: Minnetronix, Comments: Data and Safety Monitoring Board; Grants/Grants Pending: Sequent Medical, Codman, NeuroSigma, Medtronic, MicroVention, Comments: preclinical research and clinical trials.* Saruhan Cekirge-UNRELATED: Consultancy: Medtronic, MicroVention, Sequent Medical. *Money paid to the institution.

\section{REFERENCES}

1. Kavalipati N, Shah J, Ramakrishan A, et al. Pleiotropic effects of statins. Indian J Endocrinol Metab 2015;19:554-62 CrossRef Medline

2. Puato M, Zambon A, Faggin E, et al. Statin treatment and carotid plaque composition: a review of clinical studies. Curr Vasc Pharmacol 2014;12:518-26 CrossRef Medline

3. Hiroyuki K, Daida M. Impact of intensive lipid lowering therapy on carotid plaque instability assessed by MRI; challenger trial: carotid plaque in human for all evaluations with aggressive rosuvastatin therapy-evaluation by magnetic resonance imaging. $J$ Am Coll Cardiol 2014;63(suppl):A1046 CrossRef

4. Yamamoto H, Ikuta S, Kobuke K, et al. Difference in statin effects on neointimal coverage after implantation of drug-eluting stents. Coron Artery Dis 2014;25:290-95 CrossRef Medline

5. Tentzeris I, Rohla M, Jarai R, et al. Influence of high-dose highly efficient statins on short-term mortality in patients undergoing percutaneous coronary intervention with stenting for acute coronary syndromes. Am J Cardiol 2014;113:1099-104 CrossRef Medline

6. Reiff T, Amiri H, Rohde S, et al. Statins reduce peri-procedural complications in carotid stenting. Eur J Vasc Endovasc Surg 2014;48: 626-32 CrossRef Medline

7. Kadirvel R, Ding YH, Dai D, et al. Cellular mechanisms of aneurysm occlusion after treatment with a flow diverter. Radiology 2014;270: 394-99 CrossRef Medline

8. Becske T, Kallmes DF, Saatci I, et al. Pipeline for uncoilable or failed aneurysms: results from a multicenter clinical trial. Radiology 2013; 267:858-68 CrossRef Medline

9. Kallmes DF, Hanel R, Lopes D, et al. International retrospective study of the Pipeline embolization device: a multicenter aneurysm treatment study [published Erratum appears in AJNR Am J Neuroradiol 2015;36:E39-40]. AJNR Am J Neuroradiol 2015;36:108-15 CrossRef Medline

10. Kallmes DF, Brinjikji W, Boccardi E, et al. Aneurysm Study of Pipe- 
line in an Observational Registry (ASPIRe). Interv Neurol 2016;5: 89-99 CrossRef Medline

11. Alexander MD, Rebhun JM, Hetts SW, et al. Lesion location, stability, and pretreatment management: factors affecting outcomes of endovascular treatment for vertebrobasilar atherosclerosis. J Neurointerv Surg 2016;8:466-70 CrossRef Medline

12. Khan M, Qureshi AI. Factors associated with increased rates of post-procedural stroke or death following carotid artery stent placement: a systematic review. J Vasc Interv Neurol 2014;7:11-20 Medline

13. Kim JS, Kim JH, Shin DH, et al. Effect of high-dose statin therapy on drug-eluting stent strut coverage. Arterioscler Thromb Vasc Biol 2015;35:2460-67 CrossRef Medline

14. Jang JY, Kim JS, Shin DH, et al. Favorable effect of optimal lipidlowering therapy on neointimal tissue characteristics after drugeluting stent implantation: qualitative optical coherence tomographic analysis. Atherosclerosis 2015;242:553-59 CrossRef Medline

15. Suh Y, Kim BK, Shin DH, et al. Impact of statin treatment on strut coverage after drug-eluting stent implantation. Yonsei Med J 2015; 56:45-52 CrossRef Medline

16. Uemura S. Statins and prevention of stent-related late adverse events. Coron Artery Dis 2014;25:277-78 CrossRef Medline

17. Jeger RV, Brunner-La Rocca HP, Bertel O, et al; BASKET Investigators. Stent thrombosis after coronary stent implantation: a protective effect of high-dose statin therapy? Cardiology 2013;126:115-21 CrossRef Medline

18. Spiliopoulos S, Theodosiadou V, Katsanos K, et al. Long-term clinical outcomes of infrapopliteal drug-eluting stent placement for critical limb ischemia in diabetic patients. J Vasc Interv Radiol 2015; 26:1423-30 CrossRef Medline

19. Artom N, Montecucco F, Dallegri F, et al. Carotid atherosclerotic plaque stenosis: the stabilizing role of statins. Eur J Clin Invest 2014; 44:1122-34 CrossRef Medline

20. Correale M, Abruzzese S, Greco CA, et al. Pleiotropic effects of statin in therapy in heart failure: a review. Curr Vasc Pharmacol 2014;12: 873-84 CrossRef Medline
21. Szikora I, Turanyi E, Marosfoi M. Evolution of flow-diverter endothelialization and thrombus organization in giant fusiform aneurysms after flow diversion: a histopathologic study. AJNR Am J Neuroradiol 2015;36:1716-20 CrossRef Medline

22. Park SJ, Kang SM, Park DW. Dual antiplatelet therapy after drugeluting stents: defining the proper duration. Coron Artery Dis 2014; 25:83-89 CrossRef Medline

23. Wang TJ, Yang YJ, Xu B, et al. Atorvastatin accelerates both neointimal coverage and re-endothelialization after sirolimus-eluting stent implantation in a porcine model: new findings from optical coherence tomography and pathology. Circ J 2012;76:2561-71 CrossRef Medline

24. Aoki J, Kozuma K, Tanabe K, et al. Effect of olmesartan on the levels of circulating endothelial progenitor cell after drug-eluting stent implantation in patients receiving statin therapy. J Cardiol 2014;64: 435-40 CrossRef Medline

25. António N, Fernandes R, Soares A, et al. Impact of prior chronic statin therapy and high-intensity statin therapy at discharge on circulating endothelial progenitor cell levels in patients with acute myocardial infarction: a prospective observational study. Eur J Clin Pharmacol 2014;70:1181-93 CrossRef Medline

26. Aoki T, Kataoka H, Ishibashi R, et al. Pitavastatin suppresses formation and progression of cerebral aneurysms through inhibition of the nuclear factor kappaB pathway. Neurosurgery 2009;64:357-65; discussion 365-66 CrossRef Medline

27. Aoki T, Kataoka H, Ishibashi R, et al. Simvastatin suppresses the progression of experimentally induced cerebral aneurysms in rats. Stroke 2008;39:1276-85 CrossRef Medline

28. Tadros RO, Vouyouka AG, Chung C, et al. The effect of statin use on embolic potential during carotid angioplasty and stenting. Ann Vasc Surg 2013;27:96-103 CrossRef Medline

29. Jeong HC, Ahn Y, Hong YJ, et al; Other Korea Acute Myocardial Infarction Registry Investigators. Statin therapy to reduce stent thrombosis in acute myocardial infarction patients with elevated high-sensitivity C-reactive protein. Int J Cardiol 2013;167:1848-53 CrossRef Medline 